\title{
ACTUALIDAD DE LA FILOSOFÍA IN-SISTENCIAL: EL PERSONALISMO COMUNITARIO IN-SISTENCIAL DE ISMAEL QUILES SJ.
}

\author{
RAÚL FRANCISCO SEBASTIÁN SOLANES \\ Universidad de Valencia
}

\begin{abstract}
RESUMEN: En el presente texto acerco a la propuesta de filosofía In-sistencial elaborada por Ismael Quiles, analizando varios aspectos. El primero es situar a Quiles en el contexto histórico-filosófico, analizando su formación intelectual en España y en su exilio argentino, viendo las etapas de su pensamiento. En segundo lugar, veo las relaciones de Quiles con el existencialismo de Heidegger, Sartre y Gabriel Marcel. En tercer lugar, intento justificar cómo su pensamiento está dentro de la corriente del personalismo comunitario, pero no de vertiente judaica como la de Buber, sino cristiana. En último lugar defiendo que pese a su adhesión al cristianismo, no podemos considerarle simplemente como un filósofo cristiano, sino como un filósofo que, influido por el pensamiento oriental, abre la filosofía in-sistencial a la mística.
\end{abstract}

PALABRAS CLAVE: Filosofía In-sistencial, existencialismo, personalismo comunitario, Ismael Quiles, mística.

\section{Philosophy In-sistencial at present:The in-sistencial communitarian personalism of Ismael Quiles SJ.}

ABSTRACT: This text presens the proposal of In-sistencial philosophy developed by Ismael Quiles, analyzing various aspects. The first is to place Quiles in the philosophical and historical context, analyzing his intellectual formation in Spain and in his exile in Argentina, seeing the stages of his thought. Secondly, I see Quiles relations with existentialism of Heidegger, Sartre and Gabriel Marcel. Third, I try to justify that his thinking belongs to the current communitarian personalism, but not shed Buber's Jewish orientation, but Christian. Lastly argue that despite his adherence to Christianity, we can not consider him just as a Christian philosopher, but as a philosopher who, influenced by Eastern thought, who opens in-sistencial philosophy to mysticism.

KEY WORDS: In-sistencial philosophy, existentialism, communitarian personalism, Ismael Quiles, mysticism.

\section{Contexto históRico-Biográfico de Ismael Quiles}

Conviene referir algunos datos biográficos de Ismael Quiles junto a las etapas de su pensamiento filosófico. Esto nos ayudará a situar a Quiles en su contexto históricosocial, pero también nos permitirá referirnos al contexto filosófico en que se forma y en donde desarrollará su original propuesta de Filosofía In-sistencial. Es importante conocer algunos de los rasgos de su itinerario vital pues, a diferencia de lo que pensaba Martin Heidegger defensor de la independencia entre el autor y su obra ${ }^{1}$, considero que sí existe una relación entre ambos planos. Serán precisamente muchas de estas circunstancias vitales las que marcarán para siempre su vida y su trayectoria filosófica.

1 Heidegger ha sido uno de los principales defensores de la independencia de ambos planos. Se cuenta la anécdota de que preguntado por la vida de Aristóteles y la influencia en su pensamiento, respondió: «Todo lo que tengo que decir sobre el particular es que Aristóteles nació, vivió y murió».VÁzQUEZ, M. E., «En compañía del pensador», $\Delta \alpha \mu \omega \omega v$. Revista Internacional de Filosofía, 53, 2011, pp. 171-172. 
Muy pocos saben que Ismael Quiles nace en la localidad valenciana de Pedralba el 4 de julio de 1906, hecho que va a marcar su impronta personal y profesional durante el resto de su vida, porque será en Pedralba donde reciba su iniciación al cristianismo, como él mismo dice en su libro Autorretrato filosófico ${ }^{2}$ : una cosmovisión cristiana. La habia recibido en mi niñez, la había asimilado con más precisión durante mis estudios humanísticos en el Seminario de Valencia.

Después de cursar los correspondientes estudios eclesiásticos, es enviado al Colegio Máximo de san Ignacio en Barcelona donde tiene oportunidad de profundizar sus estudios filosóficos, especialmente la filosofía oficial de la Compañía de Jesús que era la «escolástica suarista», obteniendo el título de doctor en filosofía en el año $1930^{3}$. Tras la proclamación de la segunda República en 1931 y la aprobación de las reformas educativas adoptadas por el gobierno republicano que apartaban de la educación a las órdenes y congregaciones religiosas, a las que les fueron confiscados todas las propiedades destinadas a funciones educativas, los jesuitas españoles, entre los que se encontraba Quiles, se vieron envueltos en una difícil situación donde no sólo peligraba su patrimonio material, sino sus propias vidas. Es en este momento cuando los superiores de Ismael Quiles, debido a su mala salud, deciden enviarlo a la Argentina. En 1932 Quiles parte a bordo de un barco desde Barcelona rumbo a Buenos Aires, enfermo y de incógnito en la bodega del barco.

A finales de ese año, aunque no estaba del todo recuperado, pudo iniciar sus estudios de teología en el Colegio Máximo de san Miguel, próximo a la ciudad de Buenos Aires. Aunque no pudo asistir a todas las clases, gracias a la ayuda de sus compañeros jesuitas, concluyó los estudios teológicos de manera brillante. Acabados éstos, iniciará su labor docente como profesor de historia de la filosofía y de metafísica en el año 1938, pasando definitivamente a la Universidad del Salvador, dónde quedaría vinculado de por vida. Fue Decano de la Facultad de Filosofía, Vice-rector de la Universidad desde los años 1956 a 1962, ocupando de nuevo el mismo cargo en 1965. Rector Magnífico desde octubre de 1966 a noviembre de 1970 y desde esta fecha hasta 1977, Rector de la Comunidad del Salvador y Pro-rector de la Universidad.

Su vocación por Oriente, que venía desde sus años de noviciado, se vio satisfecha a partir de 1960 gracias al viaje que realizó Quiles auspiciado por la UNESCO dentro del «Proyecto Mayor Oriente-Occidente». Durante este viaje de estudios, Quiles visita numerosas universidades asiáticas y entra en contacto con las escuelas de pensamiento oriental, especialmente con la escuela del Budismo Zen ${ }^{4}$.

Otra de las grandes pasiones de Quiles durante estos años, fue la de organizador. A nuestro filósofo se debe la fundación de la «Escuela de Estudios Orientales» de la Universidad del Salvador, de la que llegará a ser director desde el mismo año de su fundación en 1967. Fue además director del «Instituto Latinoamericano de Investigaciones Comparadas Oriente-Occidente» (ILICOO) desde el año 1973. Una prueba del reconocimiento y gratitud del mundo oriental hacia Quiles, es la condecoración en 1988 por el emperador de Japón de la «Orden del Sol Naciente», que es la máxima distinción con la que el emperador nipón gratifica a sus súbditos o a las personas que él considera dignas, siendo Ismael Quiles hasta el momento el único filósofo español condecorado con este distintivo.

Como afirma Jorge Mario Bergoglio, la obra de Quiles exuda paciencia, pues le ha tocado vivir épocas que van desde el restauracionismo a ultranza, al progresismo de

\footnotetext{
Quiles, I., Autorretrato filosófico, Depalma, Buenos Aires, 1981, p. 28.

Ibid., pp. 28 y ss.

4 Quiles, I., Autorretrato filosófico, ibid., p. 41.
} 
laboratorio más sofisticado. Quiles supo escuchar, sufrir y recoger lo bueno para aproximarse al misterio del hombre, para ayudar al hombre mismo a encontrarse dentro de sí ${ }^{5}$. Creo que las difíciles circunstancias que tuvo que atravesar Quiles, lejos de perjudicarle en su trayectoria filosófica, le beneficiaron considerablemente. Gracias a su estancia en Argentina, Quiles se ahorró el haber tenido que asistir a la guerra civil española que azotó el país de 1936 a 1939, tampoco sufrió las consecuencias de la posguerra que durará unos diez años y arrojó al país a una situación de penuria económica, política y social que hicieron que importantes escuelas filosóficas españolas como la «Escuela de Madrid» o la «Escuela de Barcelona» no pudieran continuar sus ambiciosos proyectos filosóficos. Quiles llega a Argentina en uno de sus mejores momentos económicos, gracias a ello su vida transcurre con normalidad, dejándole dedicarse a la docencia universitaria y dándole el tiempo y los recursos necesarios para sacar adelante su obra y su pensamiento filosófico in-sistencial. Ismael Quiles murió en Buenos Aires el 8 de febrero de 1993, 51 años después de que llegara al país, quedando su legado filosófico unido para siempre al país argentino, aunque pertenezca a la esencia eterna de la filosofía universal.

\section{Contexto filosófico: Etapas de su pensamiento}

Es cierto que Ismael Quiles vive poco tiempo en España, aunque su primera etapa de formación es claramente española. Por ello, vamos a recordar sus años de formación y la generación a la que pertenece. Gerardo Bolado distingue tres generaciones o grupos filosóficos en el siglo xx, a) los nacidos en la primera década, b) los nacidos en torno a los años 20 y c) los nacidos en los años $40^{6}$. Ismael Quiles pertenece a los primeros, aquellos que vivieron, por una parte, la Edad de Plata de la Cultura Española, con verdaderos maestros que ejercieron una tradición discipular, formaron equipo y crearon escuelas, la Escuela de Madrid con el magisterio de Ortega y la Escuela de Barcelona; por otra parte, a estos profesores y autores les tocó vivir la guerra civil y ésta produjo una quiebra, una verdadera ruptura, en su pensamiento. Algunos de ellos se exiliaron, como José Gaos, María Zambrano, Ferrater Mora, Eduardo Nicol, Manuel Granell entre otros y otros se quedaron, viviendo no obstante, un exilio interior: Laín Entralgo, Julián Marías, López Aranguren, entre otros.

Ismael Quiles, debido a su condición de jesuita, también tuvo que salir de España bajo la condición de un traslado, que fue forzoso, pero queremos subrayar que este hecho sucede en el contexto de la segunda República y no de la guerra civil. Esto convierte a Quiles en un filósofo «transterrado», no a consecuencia de la guerra civil, sino por el auge de la segunda República, aunque a diferencia de otros transterrados, pienso en María Zambrano o José Ferrater Mora, Quiles sí marcha al exilio siendo doctor en filosofía. Por este motivo podríamos considerarlo dentro de una categoría nueva en la historia de la filosofía española que es la de «los otros exiliados». ${ }^{7}$ Aunque algunos

5 Bergoglio, J. M., «Insistencialismo y hombre actual», en Reflexiones en esperanza, Ediciones de la Universidad del Salvador, Buenos Aires, 1990, p. 349; Bergoglio, J. M., «Prólogo», en Terrén, Ma . M., (Eda.), Persona y Acción del RP Ismael Quiles SJ, Fundación Ser y Saber-Publicaciones de la Universidad del Salvador, Buenos Aires, 2010, pp. 7-9.

6 Bolado, G., Transición y recepción. La Filosofía Española en el último tercio del siglo xx, Sociedad Menéndez Pelayo, Santander, 2001.

7 Sebastián Solanes, R. F., «Los otros exiliados en Iberoamérica: La Filosofía In-sistencial de Ismael Quiles S.J. en los países independizados», en Pena GonzÁlez, M. A. (Coord.) El Mundo Iberoamericano antes y después de las independencias, Publicaciones Universidad Pontificia de Salamanca, Salamanca 2011, pp. 665-670. 
estudios sitúan a Quiles dentro de la «generación del 25» argentina $^{8}$, creo que debemos incluir a Quiles en el grupo de la "generación sin maestros», donde destacan Fernando Cubells, Fernando Montero Moliner, Carlos Paris, José Luís Blasco Estellés y otros, que por las circunstancias de la guerra civil si vieron privados súbitamente de una tradición discipular y tuvieron que hacerse a sí mismos. Quiles se vio privado de la posibilidad de formarse en una escuela filosófica española, de nuevo, no por los acontecimientos de la guerra civil, sino por la proclamación de la República.

Según propone Alain Guy ${ }^{9}$, en el siglo xx hay un grupo de pensadores que podrían denominarse dentro de un movimiento propio del espiritualismo agustiniano entre los que se encuentran Luis Farré (1902-1997), español nacionalizado argentino, que es el patriarca de esta escuela de pensamiento, formado en la Universidad de Tucumán y de la Plata (Argentina), y que ha escrito también sobre filosofía y religión y sobre mística. Otros autores, más jóvenes que Farré y a los que Quiles apreciaba, son Basave del Valle y Caturelli, ambos nacidos en los años 20. Alain Guy propone a Quiles entre los tomistas $\mathrm{y}$ entre ellos distingue a los tomistas nacidos en la primera década del $\mathrm{xx}$, que son tomistas más integrales como Octavio Nicolás Derisi (1907, Argentina) y los moderados, casi todos nacidos en Argentina como Nimio de Anquín (1891), Juan Ramón Sepich (1906) e Ismael Quiles. Éstos son filósofos cuyo pensamiento está de acuerdo con el cristianismo, aún más, con el contenido de la Revelación. Otros autores de esta misma primera década y también tomistas moderados son: Antonio Gómez Robledo (1908) de México, Llambias de Azevedo de Uruguay (1907), Belaúnde (1883) de Perú.

Pero esta clasificación de Guy se referiría tan solo a la primera de las tres etapas que experimenta el pensamiento filosófico de Ismael Quiles y que no se reduce al tomismo ni a la escolástica. Quiles se sentirá en deuda con el tomismo y con la filosofía escolástica, especialmente la suarista, pero también con el existencialismo, especialmente el de Gabriel Marcel, que supone la fuente de inspiración que le llevará a elaborar su filosofía in-sistencial. La filosofía de Quiles incorpora un elemento novedoso en el panorama actual de la filosofía que es la síntesis entre el pensamiento oriental con el occidental. Dicha síntesis le ayuda a superar problemas centenarios que venía arrastrando la filosofía occidental.

El pensamiento filosófico de Ismael Quiles, como en el caso de los grandes sistemas filosóficos de la historia, no ha surgido de la nada irrumpiendo de improvisto, pues ha experimentado una génesis y una evolución. En su Autorretrato filosófico, Quiles nos hace un breve pero intenso recorrido de su pensamiento, dividiendo en tres las etapas de génesis de su filosofía:

La primera etapa es la que denomina «Etapa racional», que va desde el año 1938 al año 1948. Durante este período, su pensamiento sigue moviéndose dentro de los horizontes de la escolástica suarista en la que había sido iniciado desde muy temprano y de la que siempre se sintió deudor. Su principal inquietud filosófica aborda asuntos como la importancia de hallar la certeza en la experiencia vital de nuestra autoconciencia, pasando por los problemas del ser, sus principios, causas o el problema del hombre, de su relación con lo Absoluto y con su destino, siempre apoyado en principios racionales ${ }^{10}$.

En este período, Quiles se siente muy preocupado por comprender cuál es el puesto del hombre en el cosmos, en el mundo y en la historia. La posición de Quiles era muy

\footnotetext{
8 Garrido, M. (et al)., El legado filosófico español e hispanoamericano del siglo XX, Cátedra, Madrid 2009 , p. 1128.

9 GuY, A., Histoire de la philosophie espagnole, Association des Publications de l'Université de Toulouse le Mirail, Toulouse 1983

${ }_{10}$ En esta etapa cabe incluir sus obras: La persona humana, Metaphysica Generalis sive Ontologia, La Esencia de la Filosofía Tomista, Filosofía de la Religión, Filosofía y cristianismo.
} 
clara al respecto, pues sólo tenía que apoyar su reflexión sobre dos bases fundamentales: la primera era la racional, para de este modo probar la dependencia del mundo y del hombre respecto del Ser Supremo, que es su creador; y la segunda, era la histórica, que le permitía mostrar que la revelación cristiana era una base de su fe, que no es supra-temporal y supra-histórica, sino que surge en un momento histórico y su presencia sigue vigente en la historia hasta llegar a nuestros días.

Quiles considera valiosa la base filosófica de la escolástica, no sólo por su contenido de carácter «fundamental» $\mathrm{y}$ "perenne» que le ayudó a situarse de forma crítica y segura a la hora de entender al hombre y al universo, sino también porque le ofreció un método de análisis junto con un hábito de precisión y una actitud serena, que le permitía distinguir los diversos elementos de cada problema dentro de la totalidad de elementos, clasificando cada uno de ellos y distinguiéndolos de los demás según su naturaleza ${ }^{11}$. Durante este primer período, Quiles también se siente especialmente atraído por el estudio y valor del conocimiento, siendo René Descartes uno de los filósofos a los que prestó una mayor atención, debido precisamente al problema de la certeza del conocimiento que el pensamiento cartesiano supo estudiar de forma tan brillante. Las teorías del conocimiento que aportaban un elemento integral en la búsqueda del fundamento último del valor del conocimiento del hombre le resultaban atractivas, pues aportaban una solución integral para el hombre. Pero sin embargo, no eran suficientes para responder a todas las inquietudes que estaban aflorando poco a poco en Quiles. En efecto, para Quiles el primer paso cartesiano de la búsqueda de certeza epistemológica le resultaba del todo acertado, pero no era suficiente, pues los otros pasos del método cartesiano le resultaban carentes de lógica y de realismo ${ }^{12}$. Fue en el libro de Gabriel Picard titulado Le probleme critique fondamentale de 1923, donde encontró la base de para ver que la experiencia personal de cada uno, tiene que estar en contacto con lo real.

La segunda etapa corresponde a la «Etapa In-sistencial» que parte del año 1948 y que llega al año 1960. Esta etapa es verdaderamente importante en la evolución del pensamiento filosófico de Quiles, pues va a marcar la dirección de éste en adelante, hasta llegar a su síntesis del pensamiento occidental con el oriental.

Quiles ve inapropiadas las propuestas del existencialismo que sostienen Heidegger y Sartre. En el caso de Heidegger, su propuesta nos conduce a la finitud de la existencia humana, a un ser arrojado en el mundo que se angustia y extraña, debido a su condición de «ser ahí» (Dasein). Mientras que el pensamiento de Sartre, conduce la existencia humana a la nada, al sin sentido más profundo y a la desesperación existencial. Quiles quiere evitar reducir la existencia humana a la finitud y a la nada. Por eso parte de la esencia más íntima y esencial del hombre, a la que el denominará «in-sistencia». En este período cabe destacar importantes publicaciones como son: La proyección final del existencialismo ${ }^{13}$; Heidegger: el existencialismo de la angustia ${ }^{14}$; Sartre y el existencialismo del absurdo ${ }^{15}$; Sartre y su existencialismo ${ }^{16}$.

Será en esta época cuando publique Más allá del existencialismo ${ }^{17}$, donde irá aproximándose cada vez más a su filosofía In-sistencial. Debemos exponer algunos rasgos de

11 Quiles, I., Autorretrato filosófico, op. cit., pp. 32 y ss.

12 Ibid., p. 33.

QuiLEs, I., La proyección final del existencialismo, Mendoza, 1949.

Quiles, I., Heidegger: el existencialismo de la angustia, Buenos Aires, 1948.

Quiles, I., Sartre y el existencialismo del absurdo, Buenos Aires, 1952.

Quiles, I., Sartre y su existencialismo, Madrid, 1952.

17 Quiles, I., Más allá del existencialismo: una filosofía del ser y la dignidad del hombre. Barcelona, 1958. 
su pensamiento in-sistencial para comprender hasta qué punto quiere cribar de manera original los presupuestos del existencialismo de Heidegger y Sartre, pero también corresponde ver hasta qué punto Quiles se siente en deuda con la corriente existencial, especialmente con la de Gabriel Marcel.

Esta segunda etapa de su pensamiento marcará de ahora en adelante la trayectoria filosófica de Quiles, ahondado en todos los aspectos relacionados con la interioridad del hombre, haciendo un análisis de la realidad vivida en la experiencia humana. En definitiva se trata de una concepción de hombre que Quiles expresa con la palabra in-sistencia ${ }^{18}$. Será entonces cuando Quiles verá cómo las demás definiciones que se han dado sobre el hombre a lo largo de la historia de la filosofía le resulten "periféricas» ${ }^{19}$. Aunque será en esta etapa cuando empiece a visualizar que la verdadera esencia del hombre y su fundamento último reside en Dios, a quien nuestro filósofo denomina «Sistencia Absoluta» o «Tú Absoluto», que es en última instancia en quien encuentra su sentido y razón de ser la toda in-sistencia individual, salvándole de una vida errante, angustiosa y condenada a la nada y devolviéndole su verdadera dignidad. En esta etapa, Quiles descubre el verdadero fundamento del hombre, pero también su lugar en la historia y en la sociedad, ya que vive en sociedad y dentro de la historia, pues el hombre sólo puede instalarse en el cosmos y en la historia "desde el ser en-sí» y «desde sí». De este modo, afirma Bergoglio, Quiles se aproxima al misterio del hombre, evitando una reflexión aséptica o descarnada del hombre, pues sabe hablar del hombre de hoy y de los problemas que le acechan: la alienación del hombre mismo y el humanismo sin Dios ${ }^{20}$.

Y una tercera etapa de su pensamiento es la que denomina «Síntesis de Oriente y Occidente» que va desde el año 1960, hasta el final de su vida. En esta etapa el principal objetivo de Quiles es el de aproximarse desde su condición de pensador occidental a los pueblos orientales, para ver cómo es su visión del mundo y del hombre con la intención de captar e introducir en su filosofía la idea oriental acerca de la esencia del hombre. Será en esta etapa cuando publique su opera magna titulada Antropología filosófica insistencial, donde puede apreciarse la plena madurez de su pensamiento filosófico.

Se centrará en la aportación del Budismo Zen, pues los seguidores de esta escuela, consideraban que la esencia del hombre se descubre mirando a su interior, sólo que Quiles entenderá que no se puede quedar en el interior, ya que es necesario sobrepasar la experiencia del "yo» abriéndose a los otras individualidades y sobre todo a lo Absoluto, es decir, a Dios, al «Tú Absoluto ${ }^{21}$, que representa la In-Sistencia plena, y que viene a ser el hacedor de toda «in-sistencia» individual.

Gracias a un viaje de estudio financiado por la UNESCO, Quiles puede viajar por las diversas universidades de Asia y entrar en contacto con siglos de pensamiento y tradición oriental. En este viaje por toda Asia, Quiles logrará conocer más sobre la cultura de los pueblos del lejano oriente, pero no sólo la sabiduría acumulada en los libros, sino la forma de vivir que tienen sus gentes. A partir de su concepción filosófica in-sistencial, basada en la interioridad, como método y metafísica del hombre, hallará enseguida cierta coincidencia entre su propuesta filosófica con el pensamiento oriental.

18 Bergoglio, J. M. «Insistencialismo y hombre actual», op. cit., p. 333.

19 Quiles, I., Autorretrato filosófico, op. cit., p. 41.

20 Bergoglio, J. M. «Insistencialismo y hombre actual», op. cit., p. 336.

21 En la idea de un «Tú Absoluto» que en el pensamiento filosófico de Quiles se asocia al propio Dios, creemos que existe un paralelismo con la noción de «Tú eterno» con la que el filósofo personalista Martin Buber se refiere a Dios y que quizás probaría una influencia indirecta del pensamiento de Buber sobre Quiles. Buber, M. Yo y Tú. (Tr, de Carlos Díaz). Caparrós editores. Madrid, pp. 69 y ss. 
Esta coincidencia estaba en que tanto para Quiles como para el pensamiento del lejano oriente, la esencia del hombre se descubre mirando a su interior.

Gracias a las enseñanzas de los maestros budistas vivientes y sobre todo al budismo Zen, Quiles descubre que desde el interior del sí hay que sobrepasar la experiencia del "yo in-sistente» para descubrir que el verdadero ser interior y último es idéntico al Primer Principio y Única Realidad universal: el Absoluto. La realidad del Tú Absoluto, que para Quiles es el Dios cristiano y no debe confundirse con el dios de los filósofos. De este modo debemos situar a Quiles entre el grupo de pensadores que desde el personalismo comunitario plantean un diálogo entre el hombre y un «Tú Absoluto», pero a diferencia de autores como Lévinas o Buber, que se vinculan a una deuda con el judaísmo ${ }^{22}$, en Quiles encontramos una deuda con el cristianismo ${ }^{23}$.

\section{Quiles ante el Existencialismo de Heidegger}

La posición de Quiles frente al existencialismo de Heidegger o Sartre no debe entenderse como una crítica, en donde se intenta destruir al existencialismo, tal y como han querido hacernos ver algunos de los estudiosos de Quiles, sino más bien debe entenderse como un intento por precisar a fondo aquellas carencias a las que no ha sabido responder desde esta corriente ${ }^{24}$. La intención de Quiles es cribar tanto lo válido como lo inválido del existencialismo, registrando cuales han sido los aciertos o errores de esta corriente filosófica, además de justificar la lógica y fundamento del existencialismo y de la que en el fondo él está discrepando ${ }^{25}$.

El impacto que causa el existencialismo en la génesis y desarrollo de la filosofía insistencial de Quiles es fundamental y necesario ${ }^{26}$. El mismo Quiles nos lo hace saber en su libro Más allá del existencialismo, en donde señala cómo su idea de in-sistencia había brotado como fruto de una meditación en la que pretendía hallar los últimos motivos de las deficiencias que, según Quiles, podían encontrarse en la filosofía existencial de Heidegger y en los demás autores de esta corriente ${ }^{27}$. Sin embargo, la reacción de Quiles frente al existencialismo y a sus principales autores es algo tardía, pues la primera obra que escribe sobre el tema titulada Heidegger: el existencialismo de la angustia, ve la luz en 1948, mientras que la principal obra de Heidegger Ser y tiempo había aparecido en escena en 1927 y ya gozaba de un gran respaldo y aceptación por parte de la academia cuando Quiles inicia su andadura filosófica in-sistencial. Esta demora por parte del pensamiento de Quiles en abordar el existencialismo, se debe principalmente a una serie de circunstancias personales en su vida, como son su formación religiosa preliminar y su iniciación en la escolástica suarista, que irá declinando hacia nuevas inquietudes filosóficas de actualidad en ese momento.

El siglo xix filosófico y su pasión museística por la Historia acabaron con la irrupción en el panorama filosófico de una nueva tendencia encabezada por Martin Heidegger. Si Nietzsche despertó a la Historia de la filosofía del sueño dogmático del historicismo

22 Díaz, C., El humanismo hebreo de Martín Buber, Fundación E. Mounier, Colección Persona, Madrid, 2004, p. 137.

23 Domingo Moratalla, A., El arte de cuidar, atender dialogar y responder, RIALP, Madrid, 2013 p. 213.

24 Quiles, I., Autorretrato filosófico, op. cit., p. 41.

25 IBÁÑ̃z, R., "La actitud de Ismael Quiles, S.J. ante el existencialismo», en VII Coloquio Internacional de Filosofía Personalista In-sistencial», Depalma, Buenos Aires, 1997, p. 261.

26 Ibid., p. 257.

27 Quiles, I., Más allá del existencialismo, op. cit., p. 13. 
«pseudo-vitalista» que dominaba el panorama de su época, será Heidegger quien imponga el ritmo del nuevo caminar ${ }^{28}$.

En Introducción a la filosofía, Heidegger sostiene que la pregunta que tradicionalmente se ha venido haciendo en filosofía, es la pregunta por el fundamento, es decir, por la razón, la causa, el origen o los principios sobre los que se asienta el saber filosófico. Por esta razón, su intención desde el comienzo será la de salir de esta preocupación tradicional del quehacer filosófico y abrirse a nuevos horizontes. Para llevar a cabo este propósito Heidegger cree que debemos dejar a un lado la lógica del fundamento, pues se debe desbordar lo que ha venido siendo la tarea filosófica. Dicha tarea ha estado demasiado preocupada por encontrar un fundamento firme, sobre el que consolidar todo su edificio conceptual y que ha dejado de lado otros lugares que, quizás por su naturaleza inquietante, han sido pasados por alto, como es el de la nada ${ }^{29}$.

Heidegger es el responsable de una nueva revitalización de lo que tradicionalmente se ha entendido por «metafísica» y «ontología» pues la reflexión sobre el ser y el existir comienza desde aquel lugar, que por su naturaleza inquietante había quedado al margen de la reflexión filosófica: la nada. En ¿Qué es metafísica?, Heidegger ya se propone hablar de metafísica pero no en sentido tradicional, aunque el mismo título del libro nos induzca a ello, pues su intención es tratar una determinada cuestión metafísica ${ }^{30}$.

Con Ser y tiempo, Heidegger irrumpe en la historia de la filosofía, pero no desde el horizonte de problemas de la filosofía contemporánea, pues su pretensión es la de enlazar directamente con la cuestión nuclear que definió clásicamente la filosofía, pero desde un nuevo enfoque. Se trata de reiterar, de traer de nuevo adelante, algo que ya había sido iniciado por la filosofía clásica, pero que había sido olvidado o pasado por alto por gran parte de los filósofos contemporáneos: el olvido del ser $^{31}$. Pero traer de nuevo a colación esa tarea, entraña una modificación y no una repetición mecánica. Así Ser y tiempo se nos ofrece como una obra original, que alcanza precisamente su notoriedad recogiendo y resumiendo la filosofía precedente, no como una repetición sistemática, sino como una nueva elaboración y un nuevo enfoque de los temas trabajados por los filosofía clásica, sobre todo en relación con el ser y la existencia ${ }^{32}$.

Cómo señala Leyte ${ }^{33}$, Heidegger no termina de recoger los restos que ha dejado la filosofía clásica, pero se trata de unos restos singulares y concretos a los que acabará llamando «lo no pensado». Es llamado precisamente «lo no pensado», porque no pertenece a lo pensado. En definitiva, el intento de Heidegger es plantear de nuevo la pregunta por el ser, pues el ser mismo es lo «no pensado». En efecto, el ser es la pregunta misma por el ser y ésta ocurre como operación del Dasein, que desde la misma introducción a Ser y tiempo se presenta como el ámbito del preguntar y del ser, es un ente que consiste en ser, mientras que la existencia es un modo de ser del propio $d a-$ sein, entendiendo por existencia estar fuera («ex») de donde el ser está («sistere») ${ }^{34}$. El hombre irrumpe en el mundo ayudándose a llegar a ser él mismo. Por eso la pregunta inicial no puede ser la del fundamento, pues lo buscado ahora es la nada, ese lugar que por resultar inquietante a la naturaleza humana, ha sido tradicionalmente desplazado

28 Domingo Moratalla, A., El arte de poder no tener razón: La hermenéutica dialógica de $H$. G. Gadamer, Publicaciones Universidad Pontificia de Salamanca, Salamanca, 1991, p. 40.

29 Heidegger, M., Introducción a la filosofía. (Tr, de M. Jiménez), Madrid, 1999, p. 62.

30 Heidegger, M., ¿Qué es metafísica? (Tr, de A. Leyte), Hitos, Madrid, 2000.

31 LeYTe, A., Heidegger, Alianza Editorial, Madrid, 2005, p. 56.

32 LEYTE, A., Heidegger, ibid., p. 57.

33 Ibid., p. 58.

34 Ibid., p. 81. 
del pensamiento y omitido, pues se ha entendido «la nada» como la negación de lo ente, es decir, cómo la negación de la existencia ${ }^{35}$. El tema de «la nada» se convierte en un aspecto clave para entender la propuesta existencialista de Heidegger. Como señala Arturo Leyte $^{36}$, Heidegger con el término «nada» no está apuntando a la vieja oposición entre «ser» $\mathrm{y}$ «nada»; sino más bien entre «la nada» $\mathrm{y}$ «lo ente». ${ }^{37}$

Aclarados algunos aspectos referentes al existencialismo de Heidegger, paso a exponer en qué puntos discrepa o concuerda la filosofía in-sistencial de Quiles con el propio Heidegger.

El problema de fondo, es que el existencialismo ha dejado inconcluso el interrogante del que había partido, arrojando a la existencia y al ser, dejándoles perdidos en una nebulosa que no sabe definir las coordenadas precisas de la existencia humana.

Por esta razón señala Celia Lynch, que el gran problema que se le ofrece al insistencialismo de Quiles, radica en que el existencialismo de Heidegger no ofrece una definición a priori del hombre, pues el hombre es arrojado a un mundo exterior en donde tiene que ir haciéndose en la medida en que continua existiendo. Sólo cuando el ser humano toma conciencia de su vida sabe que "está ahí», es decir, sabe que existe. La existencia vendría a ser una permanente pérdida y reconquista, lo que produce una gradual situación de angustia en el hombre. Quiles entiende que el fracaso del existencialismo de Heidegger no sólo se produce cuando lanza la existencia del hombre hacia el exterior, sino también por conducir al hombre a una situación de angustia y de estar perdido ${ }^{38}$.

Se trata del "fracaso del existencialismo» que no debe considerarse un motivo de desánimo desde la filosofía, sino como una toma de conciencia que nos haga ver la carencia esencial del existencialismo, para así dirigirnos hacia otra dirección que nos haga ver ese lado olvidado por Heidegger y que tiene que ver con la interioridad del hombre, que es en donde reside su esencia más originaria. Según Quiles, este «fracaso del existencialismo", ha sido provechoso y ha permitido que muchos filósofos superen las desviaciones y errores de la actitud existencialista ${ }^{39}$. Es entonces cuando surge la necesidad de "encontrarse con uno mismo», como la única manera de recuperar la realidad de la existencia humana, volviendo hacia el interior del hombre y no hacia su exterior. Es entonces cuando nace el In-sistencialismo como nuevo proyecto filosófico que toma como punto de partida la esencial interioridad, buscando la «filosofía del ser» y de la dignidad del hombre a la que él llamará «antropología filosófica insistencial». ${ }^{40}$

El existencialismo ha sido un intento de salvar al individuo, es decir, al «ser concreto», olvidado o desplazado por las corrientes filosóficas imperantes en la época ${ }^{41}$. El existencialismo aparece como una corriente filosófica que quiere plantearse desnudamente el problema de la esencia y destino del hombre intentando resolverlo con toda sinceridad, crudeza y ausencia de presupuestos. Sin embargo, el existencialismo deja inconcluso el interrogante de donde había partido, porque la existencia y el «ser en cuanto ser» de

35 Heidegger, M., ¿Qué es metafísica?, op. cit., p. 97.

36 LeYte, A., Heidegger, op. cit., p. 166 y ss.

37 Heidegger, M., Ser y tiempo. (Tr, de José Gaos), F.C.E., Madrid, 2001, p. 117.

38 LyNCH, C., "La filosofía de la in-sistencia como respuesta al existencialismo», en VII Colóquio Internacional de Filosofía Personalista In-sistencial, Publicaciones Universidad del Salvador, Buenos Aires, 1997, p. 248.

39 Quiles, I., Más allá del existencialismo, op. cit., pp. 5 y ss.

40 Quiles, I., Antropología filosófica In-sistencial, Buenos Aires, 1978, p. 6.

41 Quiles, I., Más allá del existencialismo, op. cit., p. 17. 
Heidegger, quedan perdidos en una nebulosa que no permite definir las coordenadas precisas de la existencia humana ${ }^{42}$.

El análisis etimológico del término «existencia», nos conduce hacia la exterioridad, se refiere a «estar fuera». Por ello, desde el existencialismo se reduce la esencia del hombre a su existencia, convirtiéndole en un ser arrojado, lanzado hacia fuera y abandonado en el mundo. Así nos lo hace saber el mismo Heidegger cuando habla del dasein, "ser ahí» o existencia, que es esencialmente inherente al «ser en un mundo», es decir, a su condición de arrojado en un mundo previamente constituido, de la mundanidad, desde el cual debe situarse y comenzar a existir ${ }^{43}$.

Quiles, a través de la crítica que realiza hacia el existencialismo, pretende recuperar la plena subjetividad e interioridad del hombre, para evitar que el hombre acabe perdido en el mundo de la exterioridad, en un vacío existencial ${ }^{44}$. El problema del pensamiento de Heidegger radica, según Quiles, en que pone como presupuesto previo la «ex-sistencia», llegando a afirmar que ésta es la esencia misma del hombre. Por eso en su conocido texto Carta sobre el humanismo dirá que la existencia del hombre es el modo en que el hombre es esencialmente su propia esencia, el estar extático en la verdad del ser ${ }^{45}$.

Quiles encuentra dos puntos en donde según él falla la propuesta de existencialismo llevada a cabo por Heidegger ${ }^{46}$ : 1) En primer lugar, Heidegger niega que la existencia, en tanto que verdad del hombre arrojado fuera de sí, hacia el exterior, sea el fundamento mismo del hombre. Esto se debe a que Heidegger quiere desvincularse de lo que ha venido haciendo la filosofía contemporánea en los últimos tiempos, demasiado preocupada por hallar un fundamento firme y último. Sin embargo, dirá Quiles, pese a que Heidegger no quiere buscar un fundamento último sobre el que apoyar su nueva forma de hacer filosofía, lo cierto es que se está sosteniendo en la verdad del ser que vendría actuar como fundamento, por lo que lejos de su intencionalidad inicial, sin querer Heidegger está convirtiendo a la verdad del ser en un fundamento. 2) En segundo lugar, a Quiles le resulta extraño afirmar que el hombre tenga que estar fuera de sí, para ser su propia sustancia y adquirir su existencia. Es evidente que esta posición se convierte en un contrasentido ya que resulta contradictorio que el hombre tenga que salirse fuera de sí para encontrar su propia sustancia, ya que el individuo siempre ha tenido una tendencia innata a conservar, preservar y aumentar su autonomía ontológica, como bien supo plasmar en alguna ocasión Miguel de Unamuno con la frase de Michelet: mi yo, que me arrebatan mi yo ${ }^{47}$.

\section{Quiles ante el existencialismo nihilista de SARTre}

El existencialismo de Jean Paul Sastre, es una de las corrientes filosóficas más conocidas del pasado siglo xx, gracias a la difusión de su libro El ser y la nada donde encontramos los presupuestos básicos de su pensamiento. La propuesta sartreriana es

$42 \quad$ Ibid., p. 7.

43 Heidegger, M., Ser y tiempo, op. cit., p. 23.

44 Quiles, I., Más allá del existencialismo, op. cit., p. 18.

45 Heidegger, M., Carta sobre el humanismo. (Tr, Helena Cortés y Arturo Leyte), Alianza Editorial,Madrid, 2004, pp. 32 y ss.

$46 \quad$ Ibid., p. 37.

47 GonZÁlez EgIDo, L., Salamanca, la gran metáfora de Unamuno, Ediciones Universidad de Salamanca, Salamanca, 1983, p. 47. 
considerada por muchos estudiosos de la filosofía como una extrema radicalización de las propuestas existenciales cuya aportación va más allá del propio Heidegger, pues en Sartre ya no tenemos que hablar del ser, sino de la nada. Se trata de una nada que se erige como el fundamento del hombre y que le hace volver a ser él mismo, liberándose de todos los intentos de objetivización que pretenden los demás hombres o que ha pretendido ese ser supremo al que llamamos Dios, que ha querido privar al hombre de ser él mismo, de optar por el conocimiento del bien y del mal, para tenerlo bajo su dominio opresor. Para Sartre, la nada libera al hombre de todo aquello que intenta objetivizarle y le devuelve a su autenticidad. Por esta razón Heirick Beck ${ }^{48}$, no duda en caracterizar la propuesta existencialista de Sartre como «existencialismo de la nada».

Es necesario traer a colación tres puntos centrales de la propuesta de Sartre, con los cuales Quiles se muestra en desacuerdo y trata de superarlos en sus escritos apostando por la in-sistencia.

El primero de ellos, se refiere a la situación del hombre con respecto al mundo. En efecto, cuando el hombre se auto-interroga con la pretensión de poseerse a sí mismo, se encuentra cara a cara con la totalidad del mundo. El hombre está inmerso en el mundo y le acompañan las leyes de la naturaleza de las que no puede desprenderse tan fácilmente dada su condición de ser corporal. Los hombres nacemos con unos instintos que no podemos negar, pues dada nuestra condición corporal tenemos hambre, sed, lo que provoca que en muchas ocasiones estemos bajo el dominio del instinto que marca la dirección de nuestras acciones cotidianas. En este primer punto, la existencia adquiere un doble significado, pues según Sartre, si queremos liberarnos de las leyes de la naturaleza, tendremos que permanecer en la nada y en el acto de objetivización de ésta. Lo que nos conduce a aceptar el retorno estable desde la nada, realizando un acto de volver sobre sí mismo y sobre todo defender nuestra autoposición subjetiva, frente a la objetivización del mundo y de las leyes de la naturaleza. Por esta razón en Sartre la existencia precede a la esencia ${ }^{49}$.

En este primer punto, podemos darnos cuenta de la incompatibilidad del pensamiento de Sartre con el pensamiento in-sistencial de Quiles. Esto se debe a que la in-sistencia, tal y como la entiende Quiles, comienza con una mirada a nuestra interioridad, pero no se agota en nuestra propia interioridad ya que se abre hacia los otros seres in-sistentes, hacia los otros hombres, que es lo que Quiles viene a calificar de co-in-sistencia desde una atracción y vínculo ontológicos. Pero también hacia el Creador de toda in-sistencia, que es Dios o como Quiles le llama el «Tú- Absoluto» o «Sistencia Absoluta».

En segundo lugar, la posición de Sartre pretende reconducir al hombre para que llegue a ser sí mismo, sin que interfiera nadie. Para conseguir este propósito, se hace necesario el retiro personal del hombre, la disolución de su esencia y la objetivación. El hombre debe vivir para sí mismo como expresión de la débil y propia subjetividad, librándose de todo aquello que le aleje de este cometido. El hombre debe iniciar un intento de objetivizar al otro, antes de que este otro lo haga con él llegándolo a superar. El otro se nos muestra desde la propuesta de Sartre, como un obstáculo peligroso al que tengo que trascender objetivándolo, para así evitar que él pueda objetivarme y privarme de ser sí mismo. Por tanto, según Sartre cada uno busca al otro para cosificarlo, disolverlo y «nadificarlo», pues sólo mesurando al otro, dominándolo, nos podremos librar de él y evitar su objetivización.

48 Beck, H., Ex-In-Sistencia: Posiciones y trasformaciones de la filosofía de la existencia, Depalma, Buenos Aires, 1990, p. 47.

49 BЕск, H., Ex-In-Sistencia, op. cit., p. 49. 
Esta posición de Sartre, tan puramente solipsista rompe con la pretensión de Quiles de abrir la in-sistencia del yo a las otras in-sistencias, a través de la «co-in- sistencia». Para Quiles resulta insostenible la propuesta de Sartre, ya que arroja al hombre a una situación de soledad y de angustia, le hace encerrarse en sí mismo, convirtiéndolo en un ser nada solidario en quien impera el espíritu de egoísmo.

En tercer lugar, el pensamiento de Sartre defiende un presupuesto que Quiles jamás podrá aceptar como es la nadificación de $\operatorname{Dios}^{50}$. En efecto, si Dios existe, dice Sartre, sería un sujeto absoluto, omnipotente, omnipresente y omnicomprensivo, apareciendo ante mí, como un objeto absoluto. Uno no podría evitar su limitadora, quemante y nadificante mirada. La hipotética existencia de Dios se convierte para el hombre en un obstáculo que le trae importantes consecuencias, sobre todo en lo referente a su libertad, pues al estar en manos de Dios, el hombre pierde su capacidad de ser libre, se objetiviza. Para salir de esta difícil solución, Sartre cree necesario nadificar a Dios, para defender su originalidad y librarse de la objetivización, llegando a ser sí mismo. En Sartre, el hombre se crea en profundidad a partir de la absoluta nada de Dios y, como señala Beck al respecto, sólo la total caída en el vacío de la nada más absoluta permite al hombre asomarse a la estabilidad real, convirtiéndose en un ser capaz de auto-fundamentarse y que no caiga bajo la objetivización de los otros, del mundo o del mismo Dios ${ }^{51}$.

Quiles no puede aceptar como punto de partida la nada de Dios, como condición para existir. El "yo in-sistente», comienza existiendo mirando su interioridad y no puede cerrarse en sí mismo, sino abrirse a los otros seres in-sistentes y al Creador de toda insistencia que es Dios o la «Sistencia Absoluta».

\section{Quiles ante el Personalismo existencial de Gabriel Marcel}

Jesús Conill señala que lo fundamental de la filosofía existencial de Gabriel Marcel y también de Zubiri es asumido y elaborado en perspectiva cristiana por otros pensadores como son J. Maritain, H. de Lubac, Y. Congar y K. Rahner, a los que debemos la conformación de un verdadero humanismo cristiano, en donde la humanidad consiste fundamentalmente en la libertad y la responsabilidad del individuo que decide y se compromete en las situaciones concretas de su vida cotidiana, pero abierto a la trascendencia, abierto a Dios ${ }^{52}$.

Esto será lo que más agrade a Quiles de la aportación existencialista de Gabriel Marcel, que no arroja la existencia humana a la mera finitud o la nada, sino que propician la apertura del hombre a una realidad trascendente. El pensamiento de Marcel posibilita que otros intelectuales prosigan por esta nueva aportación, que a decir de Quiles, resulta más acertada que la propuesta de Heidegger y Sartre.

En Más allá del existencialismo, Quiles reconoce que su propuesta de filosofía insistencial, no sólo surge del diálogo con el existencialismo, cuyas deficiencias intenta superar, pues la filosofía cristiana de autores como Gabriel Marcel también tiene mucho que ver en su propuesta de in-sistencialismo ${ }^{53}$

50 Tomamos la palabra «nadificación» $\mathrm{y}$ «nadificante» de la terminología empleada por H. Beck. BEcK, H., Ex-In-Sistencia, op. cit., p. 51 y ss.

51 BЕск, H., Ex-In-Sistencia, op. cit., p. 52.

52 Conill, J., El enigma del animal fantástico, Tecnos, Madrid, 1991, pp. 31 y ss.

53 Quiles, I., Más allá del existencialismo, op. cit., p. 13. 
Gabriel Marcel inicialmente elabora un «existencialismo cristiano», en el cual, a diferencia de Heidegger, no se pretende considerar el análisis de la existencia como un mero estadio preparatorio para un replanteamiento fundamental de la cuestión del ser. Marcel propone distinguir entre la objetividad y la existencia, proclamando «la indisoluble unidad de la existencia y del existente», entendiendo que la idea de la existencia, junto a la existencia misma, forman una unidad completa ${ }^{54}$. Sin embargo, Marcel termina por abandonar la encasilladora palabra de «existencialista», debido a la tendencia de los seguidores de Sartre, a la que Marcel llamó le phénomène Sartre que pretendía apartar precisamente a aquellos que habían participado en la génesis del movimiento existencial como son, Kierkegaard, Jaspers, Heidegger o Marcel, considerando a Jean Paul Sartre el único fundador de l'ecole existencialiste. Es por esta circunstancia que muchos estudiosos contemporáneos, califican a Marcel como filósofo personalista o personalista existencial ${ }^{55}$.

Marcel propone una relación singular entre «mi cuerpo» y el yo, a la que denomina «encarnación» convertido en el mysterium tremendum, que se ofrece como algo con lo que me encuentro comprometido y cuya esencia está enteramente ante mí ${ }^{56}$.

A Quiles le satisface la propuesta inicial del existencialismo cristiano de Gabriel Marcel, quien ejercerá una influencia definitiva en su propuesta de filosofía in- sistencial. El motivo de este interés reside en que el pensamiento de Marcel tiene como punto de partida y como objetivo principal de su reflexión filosófica, al hombre o más concretamente a la persona. Marcel, a diferencia de Sartre, eligió la fidelidad, la esperanza y el amor como ámbitos de realidad personal trascendentes. Ámbitos relacionales abiertos a la intersubjetividad, pues el sentido de la vida personal se atisba cuando se hace experiencia de la trascendencia en los demás con quienes co- existimos ${ }^{57}$.

Quiles comparte con Marcel la idea de que el campo de observación del hombre es todo el campo completo de la experiencia. Sin embargo Quiles ve que Marcel no sabe sacar provecho suficiente a esta consideración ${ }^{58}$.

El primer aspecto en que el pensamiento de Marcel ejerce influencia en el pensamiento de Quiles, será su idea de «existencia encarnada», pues para Quiles la insistencia del hombre se halla sumergida en la naturaleza o como dirá expresamente «encarnada» en el hombre ${ }^{59}$. La in-sistencia debe entenderse como encarnada, esto no conduce a que se vea la in-sistencia como un primer principio de carácter intelectual, pues la in-sistencia debe entenderse como algo vital, es decir, como algo esencialmente vital, pues está sujeta a mi cuerpo y ligada al mundo por medio de lazos invisible pero reales.

El segundo punto de encuentro de Quiles con Marcel, es que entiende la existencia del hombre está vinculada a la idea de esperanza que es la que da sentido a nuestras vidas y nos ayuda a reconocer la unión con el Absoluto, es decir, con Dios. Para Marcel y también para Quiles, no podemos negar la unión del hombre con Dios, pues es Dios

54 Marcel, G., «Existence et objectivité», en Journal Métaphysique. $3^{\mathrm{a}}$ ed., 1935, p. 315.

55 Cañas, J. L., "¿Renacimiento del Personalismo?, en Anales del Seminario de Historia de la Filosofía, 18, 2001, pp. 162 y ss.

56 Marcel, G., Etre et Avoir, Montaigne, Paris, 1935, p.145.

57 CAÑAs, J. L., «La vivencia personalista de la religión en Gabriel Marcel y la vivencia existencialista en Jean Paul Sartre», en Burgos, J. M; Gómez, N., (Eds). ¿Quién es Dios? La percepción contemporánea de la religión, Monte Carmelo, Burgos, 2013, p. 239.

58 IвÁÑEz, R., "La actitud de Ismael Quiles, S.J. ante el existencialismo», op. cit., p. 269.

59 Cañas, J. L., "¿Renacimiento del Personalismo?, en Anales del Seminario de Historia de la Filosofía, 18, 2001, pp. 162 y ss. 
quien nos ha creado y quien da sentido a nuestras vidas. El pensamiento in-sistencial de Quiles es un pensamiento que se abre no sólo a las otros seres in- sistentes, que viven en un determinado momento histórico, sino al hacedor de toda in- sistencia, al que denomina «Sistencia Absoluta», «Tú Absoluto» o Dios, en quien encontramos un sentido y una orientación y en quien nuestra in-sistencia finita y contingente se funde pasando a ser una «in-Sistencia». Lo Absoluto y lo misterioso, se nos ofrecen en la filosofía de Quiles, como el fundamento último del «yo in-sistente» cuya naturaleza es finita y limitada, frente a la naturaleza infinita e ilimitada del «Tú Absoluto» o Dios, lo que no impide la mística unión de las in-sistencia finita con Dios.

Tanto la propuesta de Marcel, como la que hace Quiles influido en buena medida por este último, tiene unas consecuencias positivas para el ser humano. En efecto, al abrir la in-sistencia al campo de lo trascendente y lo sobrenatural la vida del hombre adquiere un sentido y ese sentido le permite tener esperanza. Ya no se trata de la vida de un ser finito que empieza a existir arrojado en un mundo en donde la incertidumbre le acompaña constantemente y le produce una angustia vital, como ocurría en el caso del existencialismo de Heidegger; ya no se trata de una existencia que parte de la nada, de la negación de los otros y del propio Dios para llegar a ser "yo mismo», lo que tiene como consecuencia más inmediata una existencia vacía y "nauseabunda», una especie de "existencialismo nihilista», como viene a sostener Sastre. Con la filosofía in-sistencial de Quiles, la existencia del hombre adquiere un sentido, le permite vivir en la esperanza, pese a los momento de dificultad que acarrean la vida cotidiana y le permite ser él mismo desde su interioridad, desde su ser más íntimo y original que es su «in-sistencia».

\section{El Tú Eterno de Buber y el Tú Absoluto de Quiles}

Dios ocupa un lugar privilegiado dentro de la filosofía in-sistencial de Quiles, de hecho será en Dios, la «Sistencia Absoluta» o el «Tú Absoluto» como le suele denominar Quiles, dónde nuestra in-sistencia encuentra un fundamento firme y un sentido a su propia vida, a través siempre del diálogo con lo Absoluto. De esta manera se aleja para siempre de aquellos defensores del existencialismo cuyo pensamiento arrojaba al hombre a un sinsentido vital y existencial, a un absurdo que le producía una sensación de desasosiego y angustia al no encontrar un sentido y un fundamento último a su existencia, condenándole a la nada, como muestra el pensamiento de Sastre.

En este punto debemos considerar a Quiles dentro del grupo de pensadores partidarios del «personalismo comunitario» que plantean un diálogo entre el hombre, en el caso de Quiles concebido como in-sistencia, con Dios o «Sistencia Absoluta». Así nos lo hace ver el propio Quiles cuando afirma ${ }^{60}$ : la relación que entablamos con el Absoluto es el diálogo, de comunicación, de seguridad, y de confianza, porque lo experimentamos como Personal, y no como Algo indeterminado. Con la particularidad de que Quiles forma parte de los personalistas comunitarios que tiene una deuda con el cristianismo y no con el judaísmo como ocurre con Buber y Lévinas ${ }^{61}$.

En la filosofía de Quiles no sólo se hace presente el «choque óntico» que propone nuestro autor como intento de superación del existencialismo vigente y apuesta por

60 Quiles, I., Autorretrato filosófico, op. cit., pp. 55-56.

${ }_{61}$ Domingo Moratalla, A., El arte de cuidar: Atender, dialogar y responder, op cit., p. 201. 
la in-sistencia. Quiles también va a proponer un «choque teológico» en donde la presencia del «Absoluto personal»o Dios, se hace imprescindible para comprender la propuesta de filosofía in-sistencial. Cuando Quiles habla de la intersubjetividad entre la in-sistencia personal con el resto de in-sitencias individuales, señala la existencia de una «atracción ontológica» como inter-in-sistencia dirigida a modo de "vínculo ontológico» no solo hacia el prójimo, sino también hacia $\operatorname{Dios}^{62}$. Esto ha hecho afirmar a Bergoglio que detrás de esta «atracción ontológica» se halla una «memoria óntica». ${ }^{63}$

En efecto, para Quiles toda in-sistencia individual (la del «yo in-sistente») experimenta algo que se le ofrece como su fundamento último. Este fundamento último de toda in-sistencia individual, se nos manifiesta según Quiles en el Absoluto que «es por sí mismo», es decir, Dios. Este Dios al que Quiles se refiere indistintamente como «Sistencia Absoluta» o "Tú Absoluto», tiene un carácter personal como puede comprobarse en el hecho de que nosotros (in-sistencias individuales), podemos dialogar con Él, además se capta como ser absolutamente consciente de sí y de sus obras, incluido el universo y cada hombre.

Hechas estas aproximaciones creemos que ha llegado el momento de ver que posible relación guarda Dios como «Tú Absoluto» de Quiles, con el Dios como «Tú eterno» de Martín Buber.

Agustín Domingo indica que Martin Buber es el primer nombre destacado de un pensador personalista que ahonde en la realidad del diálogo. Buber plantea de manera radical y concreta la realidad experiencial del diálogo recorriendo su propia historia. Dicha historia comienza con Jacobi que describe el misterio del encuentro personal: Abro mi ojo a mi oído, extiendo mi mano, y siento inseparablemente en el mismo instante; Tú y Yo, Yo y Tú; sigue con Fitchte y Feuberbach y pasa por Kierkegaard que nos lanza el problema de pensar y vivir la diferencia radical del diálogo entre yo y tú, entre el yo y el Tú Eterno. Se trata de una matriz dialógica que hunde sus raíces en el descubrimiento de la intersubjetividad y la experiencia de un tú que se abre al Tú Absoluto trasmitido desde la corriente del judaísmo por Buber, Rosenzweig o Ebner y desde el cristianismo por Mounier, Lacroix o Marcel ${ }^{64}$ y también por el propio Quiles.

A esta altura del presente artículo, me corresponde ver si era probable que Quiles estuviera de algún modo influido por la filosofía de Buber, aunque de entrada parece que esta influencia es tan sólo aparente. Quiles deja claro en repetidas ocasiones que no quiere saber nada del carácter marcadamente fenomenológico que caracteriza el pensamiento filosófico de Buber. En efecto, Buber representa para Quiles la posición extrema, pues según Buber la esencia primordial del yo se autorrealiza sólo en la relación primordial con el Tú, tesis que se hace incompatible con la filosofía in- sistencial de Quiles ${ }^{65}$. Pero además, para Buber la relación del yo con el «Tú eterno» es también una autorrealización ya que cada tú singular es una mirada al «Tú eterno»en donde a través del tú singular la palabra básica «yo-tú» se dirige al «Tú eterno» o Dios ${ }^{66}$. En Buber, el «Tú eterno», vendría a ser el «totalmente otro», pero también el «totalmente sí mismo» y «totalmente presente», convirtiéndose en el mysterium tremendum, que aparece y abate a la vez que se manifiesta como más próximo incluso que nuestro propio yo ${ }^{67}$. Ahora bien, en Buber lo único que existe es la relación con el «Tú eterno»,

62 Quiles, I., Filosofía de la persona según Karol Wojtyla, Depalma, Buenos Aires, 1987, pp. 94-95.

63 Bergoglio, J. M. «Insistencialismo y hombre actual», op. cit., p. 345.

64 Domingo Moratalla, A. (2013). El arte de cuidar: Atender, dialogar y responder, op. cit., p. 197.

65 BЕск, H., Ex-In-Sistencia, op. cit., p. 86.

66 Buber, M., (Tr de Carlos Díaz). Yo y Tú, Caparrós, Madrid, 1999, p. 69.

67 Ibid., p. 72. 
mientras que en Quiles hay algo más que una relación fenomenológica entre el «yo in-sistente» y la «Sistencia Absoluta».

En efecto, el «Tú Absoluto» de Quiles, es el fundamento último de toda in- sistencia y es el que da sentido a cada «yo in-sistente». Quiles entiende que sólo a través de la in-sistencia podremos abrirnos a la trascendencia y descubrir que es en Dios, en donde el "yo in-sistente» encuentra la estabilidad definitiva y satisface todas sus inquietudes, otorgando sentido a in-sistir que se trasforma en un in-Sistir. Quiles no dudará en decir que pese a la condición finita del hombre, éste se abre con avidez al infinito y descubre en esta realidad infinita un apoyo total y un sentido a su propia vida ${ }^{68}$. Por este motivo, permanecer en la "Sistencia Absoluta» es la esencia última del hombre en tanto que «yo in-sistente».

En resumen podemos decir, que en Buber se da más importancia a la relación existente entre la palabra primordial "Yo-Tú» con el «Tú eterno» o Dios, pues sólo a través de esta relación con el «Tú eterno» el «yo» de la palabra básica «Yo-Tú» se autorrealiza. Quiles va mucho más allá, puesto que no se reduce exclusivamente a la relación, ni se ve plenamente autorrealizado plenamente en esta relación, ya que el "yo in-sistente» se percata de que el «Tú Absoluto» es el fundamento último de su in-sistir, pues estar en el «Tú Absoluto», permanecer en la «Sistencia Absoluta» supone la esencia última del hombre, que de un mero «in-sistir» se trasforma en un «in-Sistir».

Para cerrar este apartado, podemos decir que pese a la similitud de términos, la hipotética influencia de Buber con respecto al pensamiento filosófico de Quiles, es tan sólo aparente como puede apreciarse en el hecho de que Quiles va más allá de la fenomenología y no se reduce a la mera relación entre el yo con el Absoluto, pues Quiles encuentra en Dios, como "Sistencia Absoluta» o como «Tú Absoluto», el fundamento último y la esencia última de su condición de hombre in-sistente. Entiende al hombre como punto de partida, pues desde el fondo mismo de su "yo in-sistente», encuentra una "abertura hacia el Infinito» y gracias a ello, el hombre pasa de ser una mera in-sistencia individual finita, a encontrar su realidad y fundamento últimos, que en terminología de Quiles le hace "estar-en-Otro», "estar-en-el-Absoluto» y «estar en lo que es por sí», o lo que es lo mismo, estar en Dios como nuestro creador ${ }^{69}$.

Quiles reconoce y eleva al campo de una filosofía que es a la vez teológica-mística como la verdadera esencia de la persona ${ }^{70}$. Aproximándose a una visión de misticismo similar a la que nos trasmiten autores como Rudolf Otto, que en su libro Lo santo, obra y autor que el mismo Quiles conoce y cita $^{71}$, indicaba cómo la criatura se siente fascinada por la realidad única y total del ser trascendente, no sólo por haber sido creado, sino por ser criatura, por el sentimiento de pequeñez ante la majestad de quien se cierne sobre todas las cosas ${ }^{72}$. Pero también Henri Bergson que en la última parte de su famoso libro Las dos fuentes de la moral y de la religión habla del misticismo como patrimonio de un pequeño número de personas, vinculado a la caridad y contrario al imperialismo ${ }^{73}$. Ideas recogidas también en la célebre entrevista que Bergson concede

68 BEcK, H., Ex-In-Sistencia, op. cit., p. 86 y 87.

69 Quiles, I., Antropología filosófica in-sistencial, op. cit., p. 153.

70 Rullán Miquel, Mª . V., «La persona humana en Ismael Quiles», en Terrén, Mª . M. (Eda). Persona y acción del RP Ismael Quiles, Ediciones Universidad del Salvador. Buenos Aires, 2010, p. 238.

${ }_{71}$ Quiles, I., Filosofía de la religión, Austral, Madrid, 1973, p. 27.

72 Отто, R., Lo santo: Lo racional y lo racional en la idea de Dios. (Tr, F. Vela) Alianza Editorial Madrid, 2012, p. 31 y 33.

${ }_{73}$ Bergson, H. Las dos fuentes de la moral y de la religión. (Tr, de J. Salas y J. Atencia), Tecnos, Madrid, 1996, p. 393 y ss. 
a Jacques Chevalier titulada: «De como Bergson encontró a Dios». El célebre Premio Nobel de Literatura reconocía que: la mística debe proporcionar el medio de abordar de algún modo experimentalmente el problema de la existencia y de la naturaleza de Dios. Donde no duda en afirmar que: el verdadero superhombre es el místico.... El místico tiene una voluntad de sobrehumanidad, se siente, y tiene razón en sentirse muy por encima del común de los hombres, pero no saca de esto ningún orgullo, porque siente que por sí mismo él no sería nada ${ }^{74}$.

\section{Conclusión}

Analizados los principales aspectos del pensamiento quilesiano que me había propuesto en el presente artículo, estoy en condiciones de extraer una conclusión al respecto.

Podemos situar a Ismael Quiles dentro de la historia de la filosofía en un contexto español-argentino, siendo su primera etapa de formación la española. Por su nacimiento, estaría dentro de la primera generación de filósofos españoles nacidos en el siglo xx, según la triple clasificación realizada por Gerardo Bolado. Los acontecimientos históricos que se siguieron de la proclamación de la segunda República española y su política educativa y propiciarán el cierre y la expropiación de los colegios pertenecientes a las órdenes religiosas, lamentablemente motivaron su exilio. Esta circunstancia priva a Quiles de seguir disfrutando de las ventajas de la «Edad de Plata» de la filosofía española, que acabará con la guerra civil, pero lejos de cerrar el horizonte a nuestro filósofo, le abrirá nuevas perspectivas de investigación y le proveerá de los medios académicos necesarios para desarrollar su proyecto filosófico. Esto me inclina a considerar a Quiles dentro de la categoría de los «otros transterrados», pues a diferencia de María Zambrano o José Ferrater Mora, su exilio no es a consecuencia del triunfo del régimen franquista en España, sino por el triunfo de la segunda República. Afortunadamente Ismael Quiles parte al exilio siendo doctor en filosofía, cosa que no ocurrió en el caso de Zambrano o Ferrater Mora.

Recientes investigaciones sobre filosofía hispanoamericana, me refiero al libro El legado filosófico español e hispanoamericano del siglo xx, clasifican a Quiles de forma superficial catalogándolo dentro de la «Generación del 25», como aquel movimiento filosófico argentino que se caracteriza por el predominio de las tesis existencialistas frente a las tesis fenomenológicas ${ }^{75}$. Esta clasificación me parece un tanto parca y poco acertada si analizamos en profundidad la riqueza del pensamiento quilesiano que, como ya he mostrado, presenta tres etapas bien diferenciadas, establecidas por el mismo Quiles. He mostrado el interés de Quiles por las tesis existencialistas, incluso podemos apreciar la deuda del proyecto filosófico in-sistencial con el existencialismo. Sin embargo, la pretensión de Quiles es cribar lo sano e insano del existencialismo y abrir una nueva perspectiva que parte del interior del hombre, como su parte constitutiva más esencial, y no quedarse en los presupuestos del existencialismo de un Heidegger o de un Sartre que arrojan al hombre volcándolo a una exterioridad que le angustia o a la nada, privándole de la relación con los demás y del diálogo con Dios.

74 Chevalier, J., (Trad. Manuel Mindán Manero). «De como Bergson encontró a Dios» en Revista de filosofía, 43, 1952, pp. 552-553.

75 Garrido, M. (et al) ., El legado filosófico español e hispanoamericano del siglo XX, op. cit. p. 1128. 
La originalidad del pensamiento filosófico de Quiles también reside en la novedad de su proyecto de filosofía in-sistencial, que sitúa el punto de partida en la interioridad esencial del hombre, permitiéndole relacionarse con las otras in-sistencias personales, que lejos de ser un peligro que me arrebate mi subjetividad, como ocurre en Sartre, se convierten en parte de mí. Además Quiles abre esta filosofía in-sistencial al diálogo con Dios, a quien denomina «Sistencia-Absoluta» o «Tú Absoluto», considerándole el hacedor de toda in-sistencia individual.

Creo necesario considerar el pensamiento de Quiles dentro del personalismo comunitario con quien tiene puntos en común. En primer lugar, Quiles reconoce su deuda con Gabriel Marcel. Recordemos que muchos estudiosos de Marcel clasifican la última etapa de su filosofía dentro de la categoría de «personalismo existencial». El motivo es la pretensión de Marcel por abandonar la encasilladora palabra «existencialista», dando al traste con los ataques de los partidarios del phénomène Sarte que veían a Sartre como el creador de l'ecole existencialiste desplazando a los demás partidarios de esta corriente, incluido Heidegger, o catalogándoles de "existencialista cristiano» como hicieron con Marcel. Un argumento que sustenta esta tesis está en el hecho de que Marcel sitúa al hombre como punto de partida de su reflexión, propiciando el encuentro con los demás a través de la co-existencia y en última instancia con la realidad trascendente de Dios que se le ofrece como el mysteriun tremendum, punto de convergencia con el proyecto quilesiano.

Otro aspecto que prueba la inclusión de Quiles dentro del personalismo comunitario está en que el filósofo hispano-argentino plantea un diálogo entre la persona, entendida como in- sistencia individual, con las otras in-sistencias a través de la co-in-sistencia y finalmente con Dios como «Sistencia Absoluta» que trasforma nuestra in-sistencia en in-Sistencia. A diferencia de otros pensadores del personalismo comunitario como Buber o Lévinas, la deuda de Quiles no es con el judaísmo, sino con el cristianismo. Esto ha llevado al equívoco de considerar a Quiles como un simple partidario de una filosofía cristiana ${ }^{76}$. El pensamiento de Quiles es mucho más que una apologética del cristianismo, pues se ofrece como un choche óntico y teológico, como un proyecto antropológico que introduce en el pensamiento occidental toda la riqueza del pensamiento oriental, especialmente del Budismo Zen. La religión brota de la vida misma llegando a traspasar toda la existencia humana en sus diversas manifestaciones; la experiencia y la vivencia religiosa del hombre son la misma presencia activa de la omnipresencia de Dios. Quiles se eleva al campo de una filosofía que es a la vez teológica-mística, como la verdadera esencia de la persona, lo que me lleva a definirlo como constructor de un personalismo comunitario in-sistencial. 